\title{
The Effect of Floor and Swiss Ball Exercises Using Circuit Training Methods towards Balance, Strength, Flexibility and Muscle Endurance
}

\author{
$\underline{\text { Risfandi Setyawan }}{ }^{1}$, Hari Setijono ${ }^{2}$, Nining Widyah Kusnanik ${ }^{3}$ \\ 1,2,35port Science Postgraduate Program, Universitas Negeri Surabaya, Indonesia \\ Email: risfandisetyawan@mhs.unesa.ac.id, harisetijono@unesa.ac.id, niningwidyah@unesa.ac.id
}

\begin{abstract}
:
The purpose of this study was to analyze the effect of floor exercises and swiss ball exercises with the circuit training method on balance, strength, flexibility and muscle endurance. This research uses a quasi-experimental, floor exercise treatment and Swiss ball exercise using the circuit training method with 10 training posts. The population in this study was students of physical education and sports of STKIP PGRI Jombang 2015, with a total population of 80 male students, with an average age of \pm 19 years, height $\pm 166.31 \mathrm{~cm}$, weight $\pm 58.63 \mathrm{~kg}$. From the test of each group (paired sample) obtained a significant difference between the pretest and posttest on each variable ( $p$-value> 0.05). Meanwhile, from the ANOVA test was found out that there was a difference in the average results of the physical condition of each variable in each exercise method. The study concluded that: 1) there was an effect of floor and swiss ball exercises aided circuit training method, there is a significant enhancement of balance, strength, flexibility and muscle endurance; 2) in conventional training there was also a significant enhancement on balance, strength and flexibility. There was no significant enhancement in abdominal muscle strength, abdominal muscle endurance, and leg muscle endurance; and 3) there were significant differences between the three groups in balance, strength, flexibility and muscle endurance.
\end{abstract}

Keywords: floor exercises; swiss ball exercises; circuit training; balance; strength; flexibility and muscle endurance

\section{Introduction}

The functional ability of the athlete's body must be prepared for various tasks and conditions encountered during physical exercise and to perform in a competition, good physical condition is expected to reduce the impact of injury from dynamic movement activities during exercise. Many injuries and disorders influence the body's ability to stabilize as a result of dynamic and static movement activities. Most musculosceletal injuries occur in the dynamic movements.

The condition of instability in every movement interfere the transfer of strength, speed and power in maintaining position when performing movement techniques (Behm \& Colado, 2013). For example, running and jumping movements are characterized by the impact of eccentric loads on the lower extremities in the muscle structure of the tendons. Feddermann et al. (2014), in his study, he says that average of 4\% of athletes who competed in the 2007-2014 world athletic championships suffered injuries, resulting in time loss during running. The highest number of injuries are in the marathon and short distance events. Deteriorating balance, skills, coordination and muscle strength have also been found in athletes after lower extremity injuries (Zemková \& Oddsson, 2016). Furthermore, in the results of research by Hägglund, Waldén, and Ekstrand, (2013), in soccer players muscle injury is very common up to $37 \%$. Intrinsic risk factors for lower extremity muscle injury were identified including past injury, age, poor flexibility, and decreased muscle strength or body imbalance. In a previous 
journal Ekstrand, Hägglund, \& Waldén (2011), explained that fatigue is a factor in the cause of muscle injury; here, results of research injuries are more common at the end of the match, showing the ability of endurance and ability to recover from being still lacking. Confirming the findings of other researchers Carpenter et al. (2008), the anticipatory ability of muscles to contract in the trunk was adopted with the demands of body instability during movement, which can affect the magnitude of the rate of motion. Thus, the functional movement patterns of both jumping and running can be considered very important, especially from a perspective related to balance, strength and lower body flexibility.

The ability to produce and maintain a balance between mobility and stability along the kinetic chain when performing fundamental movements with accuracy and efficiency is needed to support functional movement in terms of achieving optimal movement techniques and minimizing the impact of injury caused by these activities, training must include muscle contraction in the body. maximum intensity, correct biomechanical movement, and good stability in order to focus and maximize strength in movement, the ability to transfer power as a result of the reaction in contact with the ground from the lower to the upper part of the body during movement supported components of the physical condition of strength, flexibility, balance and good endurance.

Maintaining postural control is a key element of performing most physical movements. While flexibility is an important contributor to sports performance, the fact that less flexibility has the potential to cause injury is supported by Hrysomallis (2009), who investigated the relationship between flexibility and injury to hip adductors. The results of this study indicate that flexibility is a parameter that can affect the risk of injury. Adequate strength throughout the body is effective in preventing potential injury, muscles with greater strength and joints with greater integrity are less prone to injury.

As the center of the kinetic chain, the nucleus is responsible for transferring power from the impact of the reaction in contact with the ground from the lower to the upper part of the body during movement maneuvers in daily activities (Colston, 2012). Core stability requires instantaneous changes by the central nervous system to elicit the right combination and intensity of muscle stiffness (i.e., stability) recruitment and system mobility demands. Stable core muscles serve as the basis on which the upper and lower extremities can accelerate and transfer power effectively, core muscles not only have a major function in stabilizing the spine for activities in sports, but also can help in the prevention and rehabilitation of health disorders on the spine (McGill, 2010).

Training in order to strengthen the core of muscles to improve performance in sports and rehabilitative activities has become increasingly popular in recent years, including training using mats, or people are more familiar with yoga, pilates, floor exercises, and using ball media or also called swiss ball, psyco ball. Swiss ball exercise is recommended for core muscle training, instability devices can provide a lower load for the extremities, but lead to higher core muscle activation (Behm et. al. 2011). Swiss ball exercise is used as a rehabilitative tool to improve posture and to rehabilitate and prevent pain in the neck and waist, because the impact of this training can increase muscle strength, endurance, flexibility, and coordination and is used to improve balance skills (Kim et al. 2014; Sekendiz et al., 2010:), Cug et al. (2012), A 10-week instability training program using a swiss ball and body weight. The results of this study indicate that the use of body weight as a load under unstable conditions can provide a significant improvement in proprioception. Similar results are shown by the research results of Seo et al. (2012: p. 11), concluded that 12 weeks of training using a swiss ball had a positive effect on physical fitness and balance ability. 
In contrast to the previous opinion in several research results presented by Zemková, Kováčiková, \& Vilman (2011), jumping is carried out on an unstable surface, the level of force generated in the concentric phase is observed to decrease by $10.3 \%$. Behm, \& Colado (2012), described a loss of force production rate of $72 \%$ for the foot extensor and $21 \%$ for the plantar flexor compared to contact with the floor and $60 \%$ when performing isometric contractions in the chesh press exercise movement, as well as a decrease in strength, power and speed. by 6$10 \%$ when the bench press exercise is performed on the surface of a swiss ball. There is evidence showing that exercise on an unstable surface results in a decrease in strength, power, speed of various movements (Sparkes \& Behm, 2010; Behm, et al, 2010). This variation in power production losses is due to differences in the degree of instability applied, or in the body's capacity to stabilize in different motion settings.

Various methods of training components of physical conditions are common in the sports, including: repetition training, interval training, continuous training, circuit training. Among the diversity of forms of training methods, the circuit training method shows the diversity of forms of exercise because it can combine or package forms of exercise for all components of physical fitness, circuit training alone is a series consisting of a number of different posts in which individuals perform a given exercise as much as possible. Over a period of time, Circuit training is designed to develop cardiovascular endurance as well as muscle strength, flexibility and endurance in important muscle groups, it is an efficient training method in terms of gains made in a short period of time (Reddy, 2012:). A training program characterized by high volume, short rest periods and includes several exercises and exercises, can be effectively used for body fat reduction (Miller et al, 2014). Paoli et al. (2010) examined the effects of circuit training loading and found that high-intensity circuit training was more effective than low-intensity circuit training for increasing muscle strength

The effect of training on stable and unstable surfaces with various training methods needs to be studied in depth, in order to identify the most effective combination of intensity, volume, rest ratio, weekly frequency and sequence of exercises to determine the effect of balance, back muscle strength, abdominal muscle strength, leg strength, flexibility and endurance of athlete's leg muscles in floor exercise training, swiss ball exercise by using circuit training method.

\section{Research Methods}

This study consisted of two sample groups, namely the experimental group, which was given floor exercise and Swiss ball exercise using the circuit training method with 10 training posts, and one control group. The total population is 60 male students, with an average age of \pm 19 years, Height $\pm 166.31 \mathrm{~cm}$, weight $\pm 58.63 \mathrm{~kg}$. Research subjects were taken from the population and then divided by using a ranking method (Ordinal pairing). This research was took place at the STKIP PGRI Jombang sports center, carried out for 10 weeks with details, one week of pre-test preparation, 8 weeks for treatment (treatment). Post test measurements were taken 48-72 hours after the last treatment, measurement test :Balance Beam Test, Sit and reach test, Leg dynamometer, Partial Curl-Up, and Bench Jump Floor exercise dan swiss ball exercise by using Circuit Training Method. 


\begin{tabular}{|c|c|c|}
\hline swiss ball exercise & floor exercise & \\
\hline Wall squat & Wall Sitt & $\begin{array}{l}\text { the research sample has understood the } \\
\text { information of the training and had } \\
\text { made a letter of willingness to take part } \\
\text { in the exercise }\end{array}$ \\
\hline Bridge on Stability Ball & Bridge on Floor & $\begin{array}{l}\text { Training program is adopted from } \\
\text { Bompa \& Buzzichelli , 2015: p. 213: }\end{array}$ \\
\hline $\begin{array}{c}\text { Single-Leg Bridge on Stability } \\
\text { Ball }\end{array}$ & $\begin{array}{l}\text { Single Leg } \\
\text { Bridging }\end{array}$ & \multirow{8}{*}{$\begin{array}{l}\text { Number of posts in each circuit: } 10 \\
\text { Number of circuit in each session: } 2-3 \\
\text { Total time of circuit training session: } 35 \\
\text { minutes break interval among } \\
\text { exercises: } 30 \text { seconds break } \\
\text { interval among circuit : } 2 \text { minutes } \\
\text { Frequency each week }: 3 \text { times in a } \\
\text { week }\end{array}$} \\
\hline $\begin{array}{l}\text { Single-Leg Hip Lift on } \\
\text { Stability Ball }\end{array}$ & Pelvic tit & \\
\hline $\begin{array}{l}\text { Single Leg Glute Bridge Off } \\
\text { the Box }\end{array}$ & $\begin{array}{l}\text { Single Leg Glute } \\
\text { Bridge Off the Box }\end{array}$ & \\
\hline $\begin{array}{c}\text { Bird dog static ballance on } \\
\text { ball* }\end{array}$ & Brid dog* & \\
\hline Stability Ball Leg Rotations & Windshield Wiper & \\
\hline Gymball Crunch leg elevated & $\begin{array}{l}\text { Crunch leg } \\
\text { elevated }\end{array}$ & \\
\hline $\begin{array}{c}\text { Unilateral bridge on stabilty } \\
\text { ball }\end{array}$ & Lying Hip Stretch & \\
\hline $\begin{array}{c}\text { Reverse Pendulum Medicine } \\
\text { Ball Twister }\end{array}$ & Reverse Pendulum & \\
\hline
\end{tabular}

\section{Results and Discussion}

\subsection{Results}

\section{a. Balance}

Balance on the swiss ball group, the average pretest data was 50.35 standard deviation \pm 36.51 seconds, posttest was 72.2 seconds with standard deviation \pm 30.70 seconds. For the floor exercise group, the average pretest data was 46.6 seconds with a standard deviation of \pm 14.37 seconds and for the posttest it was 62.1 seconds with a standard deviation of \pm 16.93 seconds. In the control group the mean pretest data was 37.4 seconds with a standard deviation of \pm 18.35 seconds, the posttest data was 50.15 seconds with a standard deviation of \pm 28.35 seconds.

\section{b. Flexibility}

The swiss ball exercise group, the average pretest data was $31.53 \mathrm{~cm}$ with a standard deviation of $\pm 5.87 \mathrm{~cm}$, the posttest was $37.03 \mathrm{~cm}$ with a standard deviation of $\pm 5.88 \mathrm{~cm}$. In the floor exercise group, the average pretest data was $33.05 \mathrm{~cm}$ with a standard deviation of \pm $6.02 \mathrm{~cm}$, the average posttest data was $41 \mathrm{~cm}$ with a standard deviation of $\pm 7.05 \mathrm{~cm}$. In the control group the mean pretest data was $34.08 \mathrm{~cm}$ with a standard deviation of $\pm 5.76 \mathrm{~cm}$, the mean posttest data was $39.68 \mathrm{~cm}$ with a standard deviation of $\pm 5.92 \mathrm{~cm}$.

\section{c. Back Muscle Strength}

The swiss ball exercise group, the average pretest data was $102.63 \mathrm{~kg}$ with a standard deviation of $\pm 19.94 \mathrm{~kg}$, the average posttest data was $112.45 \mathrm{~kg}$ with a standard deviation of $\pm 16.35 \mathrm{~kg}$. In the floor exercise group, the average pretest data was $95.50 \mathrm{~kg}$ with a standard deviation of $\pm 17.43 \mathrm{~kg}$, the average posttest data was $112.20 \mathrm{~kg}$ with a standard deviation of 
$\pm 11.66 \mathrm{~kg}$. In the control group, the mean pretest data was $98.75 \mathrm{~kg}$ with a standard deviation of $\pm 16 \mathrm{~kg}$, the average posttest data was $110.90 \mathrm{~kg}$ with a standard deviation of $\pm 14.06 \mathrm{~kg}$,

\section{d. Leg Muscle Strength}

The average pretest data of swiss ball exercise group was $139.63 \mathrm{~kg}$ with a standard deviation of $\pm 35.38 \mathrm{~kg}$, the average posttest data was $150.65 \mathrm{~kg}$ with a standard deviation of $\pm 28.97 \mathrm{~kg}$, in the floor exercise group the pretest data average was $128.58 \mathrm{~kg}$ with a standard deviation of $\pm 21.46 \mathrm{~kg}$, the average posttest data was $140.48 \mathrm{~kg}$ with a standard deviation of $\pm 18.03 \mathrm{~kg}$. In the control group, the mean pretest data was $121.98 \mathrm{~kg}$ with a standard deviation of $\pm 22.15 \mathrm{~kg}$, the posttest data average was $130.85 \mathrm{~kg}$ with a standard deviation of $\pm 20.61 \mathrm{~kg}$.

\section{e. Abdominal Muscle Strength}

The average pretest data of the swiss ball exercise group was 17.8 times with a standard deviation of \pm 5.05 times, the average posttest data was 21.45 times with a standard deviation of \pm 4.11 times. In the floor exercise group, the average pretest data was 18 times with a standard deviation of \pm 3.77 times, the average posttest data was 19.8 times with a standard deviation of \pm 4.31 times. In the control group, the average pretest data was 18 times with a standard deviation of \pm 5.51 times, the average posttest data by 19.7 times with a standard deviation of \pm 4.71 times.

\section{f. Abdominal Muscle Endurance}

The average pretest data of swiss ball exercise group was 24.4 times with a standard deviation of \pm 5.48 times, the average posttest data was 30.6 times with a standard deviation of \pm 6.30 times, in the floor exercise group the pretest data average was 25.4 times with a standard deviation of \pm 6.95 times, the average posttest data of 31.7 times with a standard deviation of \pm 7.24 times, in the control group the mean pretest data was 29.4 times with a standard deviation of \pm 10.40 times, the average posttest data was 32.8 times with a standard deviation of \pm 9.57 times

\section{g. Limb Muscle Endurance}

The average pretest data of the swiss ball exercise group was 32.6 times with a standard deviation of \pm 7.16 times, the average posttest data was 37.6 times with a standard deviation of \pm 9.05 times. In the floor exercise group, the average pretest data was 29.6 times with a standard deviation of \pm 7.48 times, the posttest data average was 38.5 times with a standard deviation of \pm 8.10 times, in the control group the pretest data average was 35.6 times with a standard deviation of \pm 8.63 times the posttest data average was 38.2 times with a standard deviation of \pm 8.63 times.

\section{h. Analysis of Variance Test (One Way Anova)}

If the value of sig. $>0.05$ then $\mathrm{H} 0$ is accepted, means that the variance of the groups being compared is the same, all groups being compared have sig values. $>0.05$. Thus, it can be concluded that the variance of all groups is the same (homogeneous). One Way Analysis of Variance Test (One Way Anova), only on the variables of balance and leg muscle strength have different averages. While the variables of flexibility, back muscle strength, abdominal muscle strength, abdominal muscle endurance, and leg muscle endurance resulted in similar average score. This decision making is based on calculations if Ftable $>$ Fcount then H0 is accepted (there is no difference in the average of all test groups). The analysis of this test uses the Turkey HSD Test. In this section there are 21 combinations of pairs that are compared on average, the average value of the balance variable in the Swiss ball exercise group with control (p-value $0.026<0.05)$ and leg muscle strength in the Swiss ball exercise group with floor 
exercise (p-value). -value $0.023<0.05)$ which has a difference. Meanwhile, the average value of all other groups is similar.

\subsection{Discussion}

Human body responds through a series of integrated changes in function that involve most of the physiological systems when faced with a physical task. Movement requires activation and control of the musculoskeletal system, cardiovascular and respiratory systems provide the ability to maintain these movements for a given period. Optimal performance in sports skills does not depend solely on absolute production of muscle strength.

Athletes are usually unaware of the complex neuromuscular processes that control posture during their moving. Mechanical problems maintaining posture are very challenging but with internal processing centers in the cerebellum parallel to anticipatory postural adjustments and proprioceptive feedback (vestibular, visual and somatosensory) (Hedayatpour \& Falla, 2015). Proprioception is defined as an individual's ability to integrate sensory signals from mechanoreceptors by determining the position of body segments and movement in space or as a specialized variation of the sensory modality of touch that includes sensation of joint movement (kinaesthesia) and sense of joint position (Han et al. 2016). Sports technique of movement skills require components of strength, flexibility and dynamic balance through core stability, allowing the body to maintain dynamic balance, relying on the propulsion system to reposition the body after external disturbances when performing technical movements in sports. As mentioned, structural supports reduce the risk of potential falls during movement.

Core muscles can facilitate greater transfer for sports performance. This type of training requires dynamic action (where muscles shorten or lengthen or controlled movement) or isometric action (where muscles are tense but no movement occurs) of the core muscles in combination with dynamic or isometric action of other muscles of the upper extremities. and below. Muscles have an elastic component that allows for energy storage and recovery, muscle contractile strength is increased through the elasticity of the muscles in the performance of sports skills. However, according to Willardson (2014), the ability to utilize this elasticity depends on the efficiency of the movement. In other words, the technique is more important than absolute strength for optimal sports performance.

Core stability is the ability of the body to stabilize the center of the body against dynamic movements of the extremities and the ability to absorb repetitive load forces in the trunk as a result of internal or external disturbances (Ezechieli et al., 2013). While Shankar \& Chaurasia (2013), core stability is the body's ability to control the entire range of motion of the joints so as not to create deformities, neurological deficits, or pain that results in paralysis.

\section{a. Analysis of floor exercises by using circuit training method on balance, strength, flexibility and muscle endurance}

The research result indicates that circuit training that focuses on the core muscles should perform single and multi exercises alternately the body up or down in different sequences in circuit training to get the same results regarding the total volume of exercise in each session, perceiving the intensity of the exercise that is different. the same, regardless of the framework of the exercise program. Study results show that progressive fatigue throughout a training session affects muscle performance. These training characteristics make the muscles well-adapted to endurance activities of more than 30 minutes. The size or crosssectional area of the muscles increases as a result of the increase in mitochondrial filaments, membranes and in muscle fibers. A greater increase in physiological ability for core muscle 
control is achieved by modifying the motion of the pelvic exercises, these exercises are performed pushing (in the hip extension phase) and resisting (in the hip flexion phase).

The concept of floor exercise focuses on the core or power that activates local muscles, especially the transversus abdominis, internal oblique muscles, diaphragm, lumbar multifidus, and pelvic floor muscles. Currently, scientific data suggest that these muscles have a major role in stabilizing the lumbo-pelvic system. The stability of the lumbo-pelvic system also depends on the central nervous system to form a stability response by programmed transversus abdominis contractions to stabilize the spine (Willardson 2007; Kuppusamy et al, 2013). With the floor exercise method, spinal control is more suppressed when the hips are challenged by internal and external forces, as a result of the reactive forces from moving the upper and lower limbs during each exercise position.

The contraction of all these muscles together keeps the spine in the most stable position (the neutral zone) and prevents the risk of injury. It is known to contract before every movement of the extremity and thus functions in keeping the center, or core of the body rigid during all movement. In this training a movement preceded by muscle tension is called a stabilizing cylinder around the spine. It is formed mainly by the muscles in the anterior abdominal muscles (transverse muscle and internal oblique muscles), posteriorly multifidus muscle and transverse muscle of loin, superiorly - diaphragm and inferiorly - muscles of pelvic fundus. Reinforcing the above opinion Johnson et. al (2013), confirmed that the pelvic fundus muscles, transverse muscles and multifidus act synergistically in the process of achieving movement. Bergson, et. al. (2010), showed that the multifidus and transversus abdominis are more involved with changes in hip and body position during hip lifting, whereas the rectus abdominis muscle is responsible for hip stability in all knee stretching exercises and for controlling extensor torsion.

Cruz et al (2011) concluded strong evidence to support the use of the Pilates exercise method at least for improving flexibility and dynamic balance abilities and for increasing muscle endurance, in another study, Hyun (2014), the Pilates training method reported significant changes in improvement Strength of the abdominal muscles, flexibility of the posterior trunk and endurance of the abdominal muscles in this study had a positive effect, but the stable performance of Pilates exercises resulted in better improvements in static and dynamic balance abilities. The results of research on stable fields Kuppusamy et al. (2013), conducted a study of mat-based pilates exercises for 6 weeks, the results showed that there was a significant increase in individuals. Yildızer, \& Kirazer, 2017), evaluated training on a stable surface on static and dynamic balance balance for 8 weeks, improving post-landing stabilization and static balance performance

The results of this floor exercise is helpful in understanding the functional stabilization of the spine. In other words, strengthening the transversus abdominis and multifidus muscles increases muscle thickness, improves lumbar stabilization, activates local muscles, especially the transversus abdominis, internal oblique muscles, diaphragm, lumbar multifidus, and pelvic floor muscles. to form a stability response with programmed transversus abdominis contractions to stabilize the spine during movement either during exercise or during sports activities

\section{b. Analysis of the effect of swiss ball exercises with the circuit training method on balance, strength, flexibility and muscle endurance}

This exercise can improve joint stability where this swiss ball exercise can activate muscles according to their functions such as abdominal muscles and intervertebral muscles. The main purpose of training with an instability device is to reduce the contact area with the 
ground by establishing an unstable condition. Sundstrup et al. (2012), suggested that the unstable surface of the swiss ball can reduce pressure around the hip and lower back region and alter proprioceptive demands thereby increasing motor control of local core muscles important for balance and stability. By improving dynamic postural control and balance, and producing a more coordinated and consistent movement pattern during movement, the possible risk of injury can be prevented (Verhagen, et. al, 2005). This core stabilization ability training involves repetition of the co-activation of the transverse abdominis and lumbar multifidus co-contraction patterns to provide local segment support. When a contraction occurs, the transverse abdominis and multifidus usually contract with one activity, by increasing tension in the thoracolumbar fascia acting like a girdle, providing stability to the lumbar spine.

Increased disturbance of instability at the fulcrum during swiss ball training resulted in increased activation of the external obliques, transversus abdominus, internal obliques, erector spinae and rectus abdominus muscles increasing disturbances to the center of mass of the body. To maintain core stability, the body must integrate sensory, motor processing, and biomechanical strategies coupled with learning responses and the ability to anticipate change. the purpose of the motor is to maintain the body's center of mass (Center of Mass) in upright postural equilibrium in an unstable gravitational field. To do so requires that the projection of the body's center of mass is maintained over the base of support formed by the foot (Welch \& Ting, 2014). greater instability due to the influence of the swiss ball causes the body to automatically stimulate the neuromuscular system to work more, allowing the increase to be associated with neural adaptation. In order to carry out constant movement efforts are required to counter the destabilizing effects of gravity and disturbances during walking, running and jumping movements, the central and peripheral nervous systems must determine the position of the center of gravity of the body relative to the gravitational force and the instability device and then execute coordinated movements to correct the deviation of the center of gravity inside the body. Physiological systems and processes used in visual balance, vestibular and somatosensory, muscle and joint proprioception.

Improvements in balance, flexibility and muscle endurance after swiss ball exercises appear to be the result of increased adaptability in unstable positions. This finding is also in line with the research of Behm et al. (2002), stated that the main goal of instability training is to improve core stability. The main goal of a training program with physioball is not necessarily to increase strength but to gain stability, improve balance, and improve proprioception abilities. Victoria \& Antoanela (2016), proprioception is the body's ability to transmit a sense of position, analyze that information and react (consciously or unconsciously) to stimulation with appropriate movements.

Romero, Martínez, \& López (2013), describe the results of a 6-week study in duration of three times per week showing an increase in balance and jumping abilities using a swiss ball and BOSU. Synergistic adjustment of body position in which the muscles used in a particular task are fixed for task-specific activity proprioception, vision and the vestibular system working in coordination between muscles, sensory receptors and the brain's central nervous system (CNS) and spinal cord. In response to visual, vestibular and somatosensory input, efferent impulses to muscles for maintaining balance involve movement of the ankle, knee and hip joints, requiring coordinated action from the ankle, thigh and lower trunk muscles. When the passive, active and nervous systems work in harmony, the body is able to better withstand external disturbances and produce maximum and efficient movement while minimizing excessive forces on the surrounding joints (Bliven \& Anderson 2014). 
The results of the study (Lee, 2008; Sundstrup et al. 2012), says that the body is challenged to stabilize its position when performing movements in an unstable position on a swiss ball, this system will work harder and have more activity in an unstable environment where stimulation on stabilizers are reduced, the instability of the ball itself is thought to rapidly activate small muscles that are not used frequently as well as stimulate the proprioception and somatosensory systems to maintain balance, contributing to increased static and dynamic balance abilities. Anderson and Behm (2003) stated that the proprioceptive system relies on information from joints and muscles to coordinate unconscious reflexes to maintain balance. Agree with the research results of Behm et al. (2010), Instability on the ball itself is thought to rapidly activate small postural muscles that are not used frequently as well as stimulate proprioception and the somatosensory system to maintain balance, contributing to an increase in static and dynamic balance abilities. An unstable ball surface requires proper strength and balance to maintain proper posture during exercise.

Swiss ball exercise movements provide unstable conditions in the joints, where the body experiences pressure to stabilize the body in every movement, therefore this exercise activates stimulation to proprioception which is integrated in several sensory motor centers and regulates automatic muscle contractions by maintaining body balance. Intrafusal muscle fibers, Golgi Tendons, and other forms of proprioception feedback assist in maintaining balance and detecting body position. Consequently, acute changes in muscle-tendon unit length, tension, muscle force production, and neuromuscular activity can alter the ability to detect (afferent proprioception) and to respond to efferent muscle activity to immediate changes in balance. In the exercise pattern with the instability device, the individual will be trained to perform movements that require extraordinary neuromuscular coordination involving the automatic interaction of unconscious motor commands and postural stability of the upper and lower body muscles (Behm et al., 2004).

An increasing the number of muscle fibers created for exercise performance is thought to increase muscle strength, thereby increasing muscle endurance from above and below the body (Kim MS, 2010: Sundstrup et al. 2012; Marshall \& Murphy, 2005), findings in Zemkova's (2016) study. ), suggesting that exercise on an unstable device is a more intensive stimulus for cardiorespiratory function than that performed on a stable surface. concluded that the unstable surface of the swiss ball can reduce pressure around the hip and lower back region and alter proprioceptive demands thereby increasing motor control of local core muscles that help maintain balance, strength and cardiorespiratory function.

It can be concluded that the swiss ball causes instability when the position of the body segment is far from the center of the ball is proper to increase the prime mover activity associated with muscle activation according to the form of movement. Muscle recruitment tends to be greater during the eccentric phase compared to the isometric phase, this may explain the increased muscle activity. In this form of exercise with lower ball placement not only requires a greater proportion of the weight of the hips to be lifted during the crunch movement but also requires greater stabilization of the torso in a horizontal position because there is no support from either the floor or the ball.

Swiss ball exercise using circuit training method can be used as a exercise program reference to improve balance, flexibility, back muscle strength, leg muscle strength, abdominal muscle strength, abdominal muscle endurance and leg muscle endurance, Additional exercise programs to improve flexibility, improve control mobility of the trunk and pelvic segments. 


\section{Conclusion}

This study shows that there is adaptation caused by the floor exercise program and swiss ball exercise. This study states that it is widely assumed that muscles with balance, strength, flexibility and joints with greater integrity are less prone to injury, so that the muscles around the joint tend to prioritize stability over power production. There was a significant improvement in the Swiss ball group compared to the floor exercise and conventional groups, due to the following reasons: reduction of the contact area, increased disruption of activity due to unstable surfaces, and control of the center of gravity at body points with limited base support from Swiss balls instability.

\section{References}

Anderson K, Behm DG. (2003). Maintenance of EMG activity and loss of force output with instability. Can J Appl Physiol 2003; 28 Suppl.: S27

Behm, D.G. and Chaouachi, A. (2011). A review of the acute effects of static and dynamic stretching on performance. European Journal of Applied Physiology 111(11), 26332651.

Behm, D.G., Colado, J.C., (2013). Instability Resistance Training Across the Exercise Continuum. American Orthopaedic Society for Sports Medicine. http://www.sagepublications.com.

Behm, D.G., Drinkwater, E.J., Willardson, J.M. and Cowley, P.M. (2010). The use of instability to train the core musculature. Applied Physiology Nutrition and Metabolism 35(1), 91-108.

Behm, D.G., Kenneth, \& Curnew. 2002. Muscle force and activation under stable and unstable conditions. J. Strength Cond. Res. 3:416-422.

Bergson C.Q, Mariana F.C., César F.A, Isabel C.S. 2010. Muscle Activation During Four Pilates Core Stability Exercises in Quadruped Position. Arch Phys Med Rehabil.

Bliven, K.C.H., Anderson, B.E. (2013). Core Stability Training for Injury Prevention. Sports Health. Nov; 5(6): 514-522. doi: 10.1177/1941738113481200

Bompa, T.O, \& Buzzichelli, C., (2015). Periodization training for sports.Third Edition. Human kinetic.

Carpenter M.G., Frank J.S., Silcher C.P., Peysar G.W. (2001) The influence of postural threat on the control of upright stance. Experimental Brain Research 138, 210-218.

Colston M. (2012) Core stability, part 1: overview of the concept. Int J Athl Ther Train. 2012;17(1):8-13.

Cruz-Ferreira A, Fernandes J, Laranjo L, Bernardo LM, Silva A. 2011. A systematic review of the effects of Pilates method of exercise in healthy people. Arch Phys Med Rehabil.;92(12):2071-81.

Cug, M., Ak, Emre.,Ozdemir, R.A., Korkusuz, F., Behm,D.G., (2012). The effect of instability training on knee joint proprioception and core strength. Journal of Sports Science and Medicine. 11, 468-474.

Ekstrand, J., Hägglund, M., \& Waldén M. (2011). Epidemiology of Muscle Injuries in Professional Football (Soccer). The American Journal of Sports Medicine - p.1-7. DOI: $10.1177 / 0363546510395879$ - Source: PubMed.

Ezechieli, M., Siebert, C. H., Ettinger, M., Kieffer, O., Weisskopf, M., Miltner, O. (2013). Muscle strength of the lumbar spine in different sports. Technology and Health Care, 21(4), 379-386.

Feddermann-D,N., Junge, A,. Edouard,P., Branco, P., \& Alonso, J,M,. (2014). Injuries in 13 international Athletics championships between 2007-2012. Br J Sports Med ;48:513522. 
Hägglund, M., Waldén, M., dan Ekstrand, J., (2013). Risk Factors for Lower Extremity Muscle Injury in Professional Soccer: The UEFA Injury Study, American Journal of Sports Medicine, (41), 2, 327-335. http://dx.doi.org/10.1177/0363546512470634.

Han, J., Waddington, G., Adams, R., Anson, J., \& Liu, Y., (2016). Assessing proprioception: A critical review of methods. Journal of Sport and Hedayatpour, N. \& Falla, D. (2015). Physiological and Neural Adaptations to Eccentric Exercise:Mechanisms and Considerations for Training. BioMed Research International. Hindawi Publishing Corporation. P; $1-7$

http://dx.doi.org/10.1155/2015/193741

Hrysomallis, C. 2009. Hip adductors' strength, flexibility, and injury risk. Journal of Strength and Conditioning Research, 23(5), 1514-1517.

Hyun, J., Hwangho, K., \& Lee, C.W., (2014). The Effects of Pilates Mat Exercise on the Balance Ability of Elderly Females. J. Phys. Ther. Sci. 26: 291-293.

Johnson G.S, Johnson V.S. (2013). Zastosowanie zasad oraz procedur PNF w leczeniu

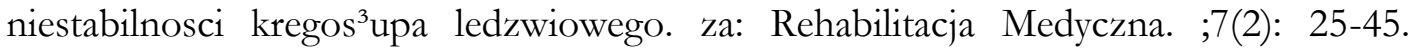
http:// www.pilatesontheball.com (Retrieved on July 2013)

Kim, S.G., Yong, M.S, Na, S.S., (2014). The effect of trunk stabilization exercises with a swiss ball on core muscle activation in the elderly. J Phys Ther Sci, 26: 1473-1474

Lee SC, (2008). Effect of 12 week Swiss ball exercise physical fitness and balance in elderly. Dissertation of Graduate School, Kook-Min University,

Marshall PW, Murphy BA. (2005) Core stability exercises on and off a Swiss ball. Arch Phys Med Rehab 2005; 86:242-9.

McGill, S.M. (2010). Core Training: Evidence Translating to Better Performance and Injury Prevention. Strength and Conditioning Journal. 32(3), 33-46,

Miller, M. B., Pearcey, G. E. P., Cahill, F., McCarthy, H., Stratton, S. B. D., Noftall, J. C.,.Button, D. C. (2014). The effect of a short-term high -intensity circuit training program on work capacity, body composition, and blood profiles in sedentary obese men: A pilot study. BioMed Research International, p: 1-10.

Paoli A, Pacelli F, Bargossi AM, Marcolin G, Guzzinati S, Neri M, Bianco A, Palma A (2010). Effects of three distinct protocols of fitness training on body composition, strength and blood lactate. J Sports Med Phys Fitness, 50(1): 43-51

Reddy, J.M., (2012). Comparison Of Circuit Training Methods On Performance Variables Of $\mathrm{Sc} / \mathrm{St}$ Non-Sc/St Boys. International Journal of Multidisciplinary Research. Vol.2 Issue 4, pp.220-228.

Romero-Franco, N., Martínez-Amat, A.Y., Martínez-López, E.J. (2013). Effect of the proprioceptive training in sprinters. Revista Internacional de Medicina y Ciencias de la Actividad Física y el Deporte. vol. 13 (51). pp. 437-451. Http://cdeporte.rediris.es/revista/revista51/artefecto393.htm

Sekendiz, B., Cug, M., and Korkusuz, F. (2010). Effects of Swiss -ball core strength training on strength, endurance, flexibility, and balance in sedentary women. Journal of Strength and Condi-tioning Research. 24(11), pp: 3032-3040

Seo, B.D., Yun, Y.D., Kim, H.R. (2012). Effect of 12-week swiss ball exercise program on physical fitness and balance ability of elderly woman. J Phys Ther Sci, 24, pp:11-15.

Shankar, G., Chaurasia, V., (2013) Comparative Study of Core Stability Exercise with Swiss Ball in Improving Trunk Endurance. International Journal of Health Sciences and Research. New Delhi, India. Vol 7. No:4, pp: 73-77.

Sundstrup, E., Jakobsen, M. D., Anderson, C.H., Jay, K., \& Andersen, L., (2012). Swiss Ball Abdominal Crunch With Added Elastic Resistance Is An Effective Alternative To Training Machines. The International Journal of Sports Physical Therapy.Volume 7, Number 4 .pp: 380. 
Verhagen, E.A.L.M., Tulder, M., Beek, A.J., Bouter, L.M. \& Mechelen, W. (2005). An economic evaluation of a proprioceptive balance board training programme for the prevention of ankle sprains in volleyball. British Journal of Sports Medicine, 39(2), 111-115.

Victoria, G.D., \& Antoanela, O,. (2016). Benefits Of The Proprioceptive Training In Recovery After Knee Sprain - Theoretical Grounds. Science, Series Physical Education and Sport / Science, Movement And Health. Vol. XVI, ISSUE 1, p: 69-73

Welch, T.D.J,. Ting, L.H,. (2014). Mechanisms of Motor Adaptation in Reactive Balance Control. PLOS ONE. 9. p:5

Willardson, J. M,. (2014). Developing the core. National Strength and Conditioning Association. Human Kinetics.

Yildizer, G. \& Kirazer, S. (2017). Effects of core stability on junior male soccer players' balance: randomized control trial. Pamukkale Journal of Sport Sciences. 8(1), pp: 48-62

Zemková, E. \& Oddsson, L. (2015). Effects of Stable and Unstable Resistance Training in an Altered-G Environment on Muscle Power. Int J Sports Med 2016; 37, pp:288-294 